\title{
SITE FIDELITY AND RETURN TRIPS OF VISUALLY AND OLFACTORILY INHIBITED BLACK ROCKFISH (SEBASTES SCHLEGELII) INDIVIDUALS TRACKED BY ACOUSTIC TELEMETRY
}

\author{
Mitsuki Kuroda \\ Yoshinori Tatsu \\ Yuya Ueda \\ Hokuto Shirakawa \\ Kenji Minami
}

See next page for additional authors

Follow this and additional works at: https://jmstt.ntou.edu.tw/journal

Part of the Fresh Water Studies Commons, Marine Biology Commons, Ocean Engineering Commons, Oceanography Commons, and the Other Oceanography and Atmospheric Sciences and Meteorology Commons

\section{Recommended Citation}

Kuroda, Mitsuki; Tatsu, Yoshinori; Ueda, Yuya; Shirakawa, Hokuto; Minami, Kenji; Miyashita, Kazushi; and Tomiyasu, Makoto (2021) "SITE FIDELITY AND RETURN TRIPS OF VISUALLY AND OLFACTORILY INHIBITED BLACK ROCKFISH (SEBASTES SCHLEGELII) INDIVIDUALS TRACKED BY ACOUSTIC TELEMETRY," Journal of Marine Science and Technology. Vol. 29: Iss. 2, Article 10.

DOI: $10.51400 / 2709-6998.1077$

Available at: https://jmstt.ntou.edu.tw/journal/vol29/iss2/10

This Research Article is brought to you for free and open access by Journal of Marine Science and Technology. It has been accepted for inclusion in Journal of Marine Science and Technology by an authorized editor of Journal of Marine Science and Technology. 
SITE FIDELITY AND RETURN TRIPS OF VISUALLY AND OLFACTORILY INHIBITED BLACK ROCKFISH (SEBASTES SCHLEGELII) INDIVIDUALS TRACKED BY ACOUSTIC TELEMETRY

\section{Authors}

Mitsuki Kuroda, Yoshinori Tatsu, Yuya Ueda, Hokuto Shirakawa, Kenji Minami, Kazushi Miyashita, and Makoto Tomiyasu 


\author{
Mitsuki Kuroda ${ }^{a}$, Yoshinori Tatsu ${ }^{a}$, Yuya Ueda ${ }^{a}$, Hokuto Shirakawa ${ }^{b}$, Kenji Minami ${ }^{\text {, }}$ \\ Kazushi Miyashita d, Makoto Tomiyasu ${ }^{\mathrm{e}, *}$ \\ a Graduate School of Environmental Science, Hokkaido University, 20-5 Benten-cho, Hakodate, Hokkaido, 040-0051, Japan \\ b Japan Sea National Fisheries Research Institute, Japan Fisheries Research and Education Agency, 1-5939-22, Suido-cho, Chuouku, \\ Niigata, 951-8121, Japan \\ ${ }^{c}$ Estuary Research Center, Shimane University, 1060 Nishikawatsu-cho, Matsue, Shimane, 690-8504, Japan \\ d Field Science Center for Northern Biosphere, Hokkaido University, 20-5 Benten-cho, Hakodate, Hokkaido, 040-0051, Japan \\ e Faculty of Fisheries Science, Hokkaido University, 3-1-1 Minato-cho, Hakodate, Hokkaido, 041-8611, Japan
}

\begin{abstract}
For fish of the genus Sebastes, which have strong site fidelity, understanding the characteristics of their return trips and how their sensory cues influence behavior will be useful for conservation and resource management. Here, we conducted a behavioral tracking study for the black rockfish Sebastes schlegelii using acoustic telemetry and sensory inhibition. We compared aspects of the return process for individuals in a control group (CNT), and fish in blind (BLD) and olfactory inhibition (OLF) conditions. Nine individuals were released $850 \mathrm{~m}$ from the fishing site, and all of them returned. However, the time taken to complete the return varied, with BLD taking the longest, followed by OLF and then CNT. One CNT individual released at $2 \mathrm{~km}$ did not return. The return route of CNT individuals was through waters shallower than $10 \mathrm{~m}$ in west receiving area, Area 1, from north receiving area including release point, Area 2, while the BLD individuals swam in the opposite direction, at a depth of $40 \mathrm{~m}$ northeast of Area 2 . OLF individuals took longer at Area 1, although they followed the same route as CNT individuals after release. Therefore, the visual cues were likely used to determine the direction of return, and the inhibition of vision probably affected return speed and activity patterns. Inhibition of olfaction likely affects the return process on small spatial scales. Though it may have less impact than visual inhibition, it may still prevent the perception of olfactory cues in specific environments and conspecifics.
\end{abstract}

Keywords: Return trips, Site fidelity, Black rockfish, Sensory inhibition

\section{Introduction}

$S$ ite fidelity is generally defined as the $\checkmark$ behavior of returning to a previously occupied place after moving to an unfamiliar place [7]. At post-migration sites, animals lack information on habitat, such as the location of conspecifics, predators, and food, and individual survival rate is expected to be reduced [14]. In fish, catch-andrelease fishing activities can result in migration independent of the fish's intentions, and information on the ecology of return to habitats and spawning sites is important from the perspective of resource management and sustainable use $[23,37,35]$.

The genus Sebastes has strong site fidelity, and many Sebastes species that leave their habitat return to the same location within a short time period $[4,17,16]$. Because of its longevity and relatively slow maturity and growth, Sebastes is likely to experience significant population declines and migration 
resulting from human activities. In some areas, the establishment of protected areas-in which the juveniles of multiple species of Sebastes are present-has been proposed [24]. Therefore, examining the characteristics of site fidelity and return trips in many Sebastes species is directly relevant to management and sustainable use of the resource.

The migratory ecology of fishes, including the genus Sebastes, has long been investigated using catch data and tagging-release surveys [4]. Attached spaghetti tags, one of the tags for animal identification to the yellowtail rockfish Sebastes flavidus and found they made return trips from a distance of $22.5 \mathrm{~km}$ [17]. Examined habitat overlap and migration trends of several species of Sebastes attached with dirt tags inserting to the animal body. Recent studies on the horizontal migration and home ranges of Sebastes have been conducted using acoustic telemetry, in which an ultrasonic transmitter is attached to animals and continuous migration is tracked $[13,18,25,19]$.

There has also been much discussion on which sensory organs of the species are used to maintain site fidelity and perform the return trips. When Sebastes return to the core area, they may primarily use their olfactory organs to trace the smell of their habitat and other individuals of the same species [8,21]. Also, many fishes learn to identify the distinctive landmarks within their home range [5,29], and the relationship between landmarks and site fidelity has been discussed in the genus Sebastes, which has more sensitive vision than other fishes $[10,21]$. However, because the characteristics of site fidelity and return trips vary by species and habitat, the use of these sensory organs must be understood in detail along with the behavioral ecology of each species.

Black rockfish Sebastes schlegelii is a benthic fish that inhabits Korea, the Chishima Islands, the Yellow Sea, and the waters around Japan [2]. Around Hokkaido in northern Japan, it is found in water shallower than $100 \mathrm{~m}$ and is often seen as bycatch in gill nets and set nets [30]. Black rockfish has a high growth rate, growing to around $25 \mathrm{~cm}$ in a year, and a narrow behavioral area within $2 \mathrm{~km}$. It is also an important aquaculture target, with 400,000-600,000 seedlings being released annually in Hokkaido $[22,11]$. In addition, artificial fishing reefs have been set up, and catch size limits have been imposed for black rockfish, making it a target species for resource management.

Regarding the migratory ecology of $S$. schlegelii [12,32], used acoustic telemetry to measure the range of horizontal migration and differences in activity during the day and at night. In addition [36],

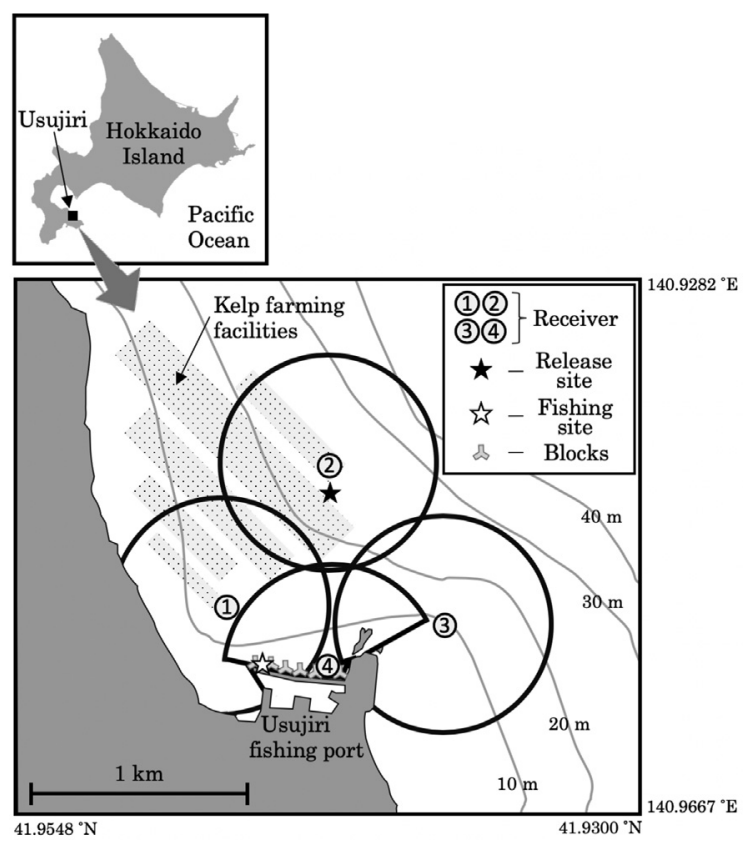

Fig. 1. Map of the study area, Usujiri fishing port in southern Hokkaido, Japan. Black circles indicated the location and the expected signal detection ranges of the acoustic receiver. The gray lines with water depths indicates contour lines.

reported return trips to a specific location and longterm site fidelity after return. However, these studies have not directly examined how members of this species migrate to their original habitat after release and which sensory organs they use during this migration. Having this knowledge will likely lead to examination of the effectiveness of stock management measures, such as the catch size limit and artificial reef establishment described above.

To investigate the behavior of black rockfish in the Hokkaido area of Japan, we conducted a study using acoustic telemetry in combination with inhibition of olfaction and vision. Based on the results, we aimed to elucidate the characteristics of site fidelity and return trips, and to verify the sensory organs used during the return trip.

\section{Materials and methods}

\subsection{Study site and duration}

The survey was conducted from 5 to 26 November, 2019 in the waters surrounding the Usujiri fishing port, located in Minamikayabe-cho, Hakodate City, Hokkaido, Japan. There were wavedissipating blocks on the north side of the Usujiri fishing port, a kelp farming facility on the northwest side of the port, and set nets on the west and north sides of the port (Fig. 1). 
Table 1. Summary of tracked black rockfish. The three individuals and transmitters were retrieval. However, the date of retrieval on the \#1 and \#5 was not detected.

\begin{tabular}{lllllll}
\hline ID & $\begin{array}{l}\text { Fork Length } \\
(\mathrm{mm})\end{array}$ & $\begin{array}{l}\text { Weight } \\
(\mathrm{g})\end{array}$ & Sex & Condition & $\begin{array}{l}\text { Release Point Distance from Fishing Site } \\
(\mathrm{m})\end{array}$ & Date of Retrieval \\
\hline$\# 1$ & 315 & 480 & $\mathrm{M}$ & CNT & 850 & ND \\
$\# 2$ & 290 & 340 & $\mathrm{~F}$ & CNT & 850 & - \\
$\# 3$ & 325 & 480 & $\mathrm{~F}$ & CNT & 2000 & - \\
$\# 4$ & 305 & 380 & $\mathrm{M}$ & CNT & 850 & - \\
$\# 5$ & 320 & 500 & $\mathrm{M}$ & BLD & 850 & ND \\
$\# 6$ & 310 & 380 & $\mathrm{M}$ & BLD & 850 & - \\
$\# 7$ & 325 & 520 & F & BLD & 850 & - \\
$\# 8$ & 300 & 420 & M & OLF & 850 & $11 / 28$ \\
$\# 9$ & 290 & 380 & M & OLF & 850 & - \\
\hline 10 & 275 & 320 & F & OLF & 850 & \\
\hline
\end{tabular}

\subsection{Survey equipment}

An acoustic transmitter (AQPX-1030P, AquaSound Inc., Kobe, Japan, frequency: $62.5 \mathrm{kHz}$, pressure: $155 \mathrm{~dB}$ re $1 \mu \mathrm{Pa}$ at $1 \mathrm{~m}$ ) and installation type receivers (AQRM-1000, AQRM-2000, AquaSound Inc., Kobe, Japan) were used for behavioral tracking. The transmitter was set to transmit sound pulses at 15-second intervals and could be tracked for about a month. This transmitter is a pinger that uses a gold code-series code; a type of cyclic code derived the maximum-length sequence with little mutual interference, and the receiver that receives the signal records the transmitter ID and reception time. The transmitter is also equipped with a pressure sensor that transmits two pulses at a basic interval of $0.05 \mathrm{~s}$ in a single transmission opportunity. At this time, information from the pressure sensor is incorporated into the transmitting time of the second pulse and the depth of tag can be estimated from the difference in the arrival time of the two pulses.

In early November 2019, four acoustic receivers were installed at specific locations around the Usujiri fishing port (Fig. 1). The maximum range of reception at the study site was $550 \mathrm{~m}$, and the radius of the four receivers was set as Areas 1 to 4 . An area overlapping with west receiving area, Area 1, and central receiving area, Area 4, was set at the fishing point of black rockfish in the north part of the Usujiri fishing port. In Area 1, receivers were installed at kelp farming facilities. In north and east receiving area, Areas 2 and 3, and Area 4, the receivers were attached to fishing gear at a depth of about $3 \mathrm{~m}$. The receivers were retrieved in late November. In order to check the reception environment around the wave-dissipating blocks, we sank the transmitter into the gap of the wave-dissipating blocks at the north side of the Usujiri fishing port and confirmed that sound waves could not be received through the
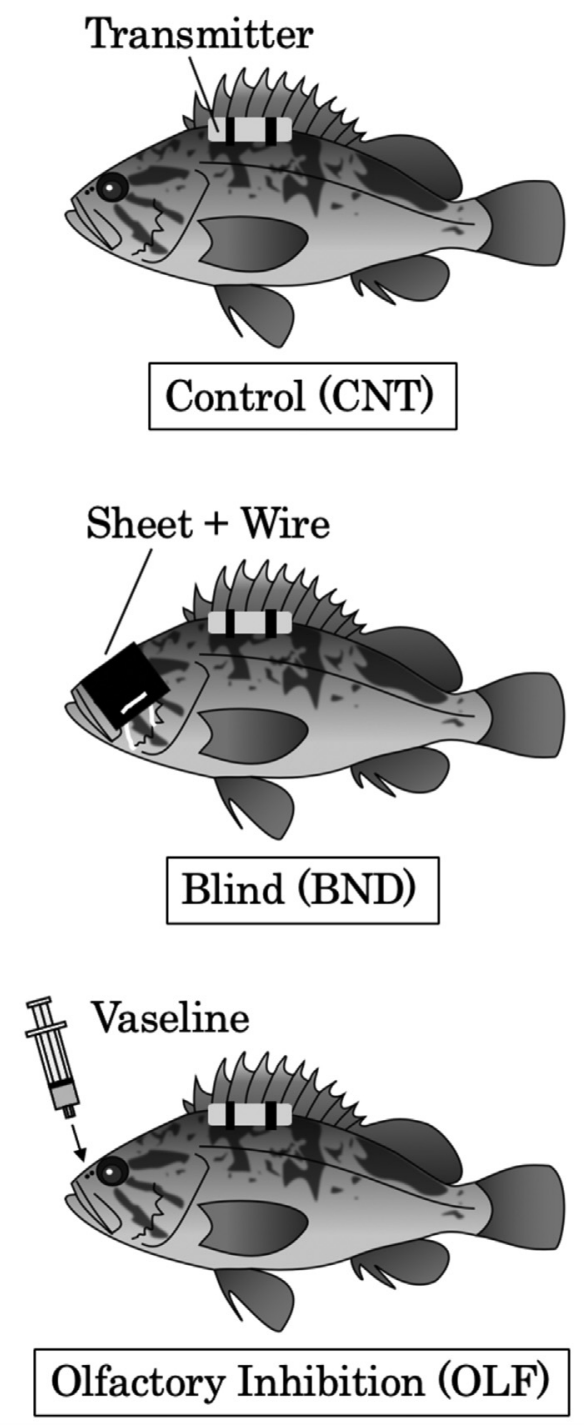

Fig. 2. Three types of conditions of tracked black rockfish: the CNT having no sensory inhibition, the BND having visual inhibition and the OLF having olfactorily inhibition. An acoustic transmitter is attached to each condition's individuals. 
gap of the wave-dissipating blocks, even if it was within the reception radius.

\subsection{Methods of tagging and sensory inhibition}

Ten individuals (Table 1) of black rockfish were caught at the tip of the north side of the Usujiri fishing port over 3 days from 6 to 8 November, 2019. Sex was determined from the reproductive genitalia near the anus. Based on the growth curve of this species [30], we determined that individuals measuring $280 \mathrm{~mm}$ or more were 2 years old.

All 10 individuals were tagged with a transmitter (Table 1). Based on previous studies [36,34], the following external tagging method was used. A hollow needle was inserted into the upper part of the dorsal fin base of an individual. The device was attached by threading a cable tie through the hole and fixing it with the stopper. Individuals recovered from tagging stress in a recovery tank for at least $12 \mathrm{~h}$, and we confirmed through direct observation that they swam normally and were not affected by the tagging.

Three out of the 10 individuals were randomly selected for visual and olfactory inhibition (BLD and OLF), and the three individuals were designated as control individuals (CNT; Table 1, Fig. 2). Sensory inhibition was performed based on previous methods [15,1,21], in which the eyes were completely covered by hooking a combination of vinyl chloride sheets and wire to the cheekbone. To confirm that vision was inhibited, we transferred the inhibited individuals to a glass water tank and ensured that they did not respond to visual stimulation from outside the tank. Olfactory inhibition was performed by filling the nasal cavities of individuals with Vaseline via a syringe [21].

At 9:44 a.m. on 13 November, 2019, nine individuals-including CNT, BLD, and OLF individuals-were released $850 \mathrm{~m}$ away from the fishing site, and one individual same condition as CNT was released $2 \mathrm{~km}$ away to verify the returnable distance.

\subsection{Analysis}

Data were collected through the reception of pulses by installation-type receivers. In this study, a single reception was defined as the receipt of two pulses transmitted at a single transmitting opportunity. The data recovery rate for the number of releases, a percentage of individuals whose transmitting was received at least once, was calculated. If the transmitter itself was retrieved, the approximate date, time, and place of retrieval and the condition of the individual were examined, and the recovery rate of the equipment in relation to the number of releases was calculated.

The number of receptions per transmitter was calculated for each receiver. By revealing the number of receptions in each area for all receptions, the utilization rate of each area was calculated. Estimated depths deeper than the maximum water depth in the receiver's installation area were removed as noise. The day and night reception times of each transmitter in each receiver were compared. Sunrise to sunset was defined as daytime, and sunset to sunrise as nighttime.

In this study, the maximum number of receptions per an hour in one area was 240 because the interval of the transmitter was set to $15 \mathrm{~s}$. Based on previous studies of the genus Sebastes [19], we defined the return to the core area as when an individual received more than $10 \%$ of the theoretical maximum number of 240 receptions in Areas 1 and 4, including the fishing site of tracked individuals. We also defined the return duration as the time required to complete the return. Next, the information from the depth sensor of the transmitter was extracted with the receiving area information using the following equation [31]:

$D=a\left[1000\left(t_{2}-t_{1}\right)-b\right]$

where $D$ is swimming depth (m), $a$ and $b$ are pressure sensor coefficients, and $t_{1}$ and $t_{2}$ indicate reception times of the first and second sound pulses

Table 2. The number of receptions in each area and return duration.

\begin{tabular}{|c|c|c|c|c|c|c|c|c|c|c|}
\hline \multirow[t]{2}{*}{ ID } & \multirow[t]{2}{*}{ Total receptions } & \multicolumn{2}{|l|}{ Area 1} & \multicolumn{2}{|c|}{ Area 2} & \multicolumn{2}{|c|}{ Area 3} & \multicolumn{2}{|c|}{ Area 4} & \multirow{2}{*}{$\begin{array}{l}\text { Return duration } \\
\text { (h) }\end{array}$} \\
\hline & & & $(\%)$ & & $(\%)$ & & $(\%)$ & & $(\%)$ & \\
\hline$\# 1$ & 9043 & 4124 & 45.6 & 3155 & 34.9 & 0 & 0 & 1764 & 19.5 & 10 \\
\hline$\# 2$ & 15833 & 11,114 & 70.2 & 1154 & 7.3 & 0 & 0 & 3565 & 22.5 & 1 \\
\hline \#3 & 69 & 0 & 0.0 & 0 & 0.0 & 0 & 0 & 69 & 100.0 & NA \\
\hline \#4 & 5952 & 3184 & 53.5 & 1346 & 22.6 & 0 & 0 & 1422 & 23.9 & 9 \\
\hline$\# 5$ & 3162 & 768 & 24.3 & 1545 & 48.9 & 0 & 0 & 849 & 26.9 & 141 \\
\hline$\# 6$ & 7129 & 3298 & 46.3 & 1743 & 24.4 & 0 & 0 & 2088 & 29.3 & 30 \\
\hline$\# 7$ & 2572 & 830 & 32.3 & 1187 & 46.2 & 0 & 0 & 555 & 21.6 & 46 \\
\hline$\# 8$ & 1852 & 1637 & 88.4 & 82 & 4.4 & 0 & 0 & 133 & 7.2 & 1 \\
\hline$\# 9$ & 10455 & 8284 & 79.2 & 563 & 5.4 & 0 & 0 & 1608 & 15.4 & 37 \\
\hline$\# 10$ & 1856 & 923 & 49.7 & 631 & 34.0 & 0 & 0 & 302 & 16.3 & 11 \\
\hline
\end{tabular}


simultaneously emitted from the same transmitter at the receiver.

Based on the history of the receiving area and depth data, we compared the swimming characteristics of CNT, BLD, and OLF individuals. The periods of comparison were the period from the release to the recovery of the receiver and the $24 \mathrm{~h}$ after the release. R. Ver. 3.6.3 [28] was used for all statistical analyses. Differences in time required to return and average swimming depth were tested using a generalized linear model, specifying a gamma ("log") distribution, with a post-hoc general linear hypothesis test [3].

\section{Results}

\subsection{Recovery of data and device}

The fork length of tagged individuals was $305.5 \pm 16.7 \mathrm{~mm}$ (mean \pm S.D.), and the sex ratio was $60.0 \%$ males and $40.0 \%$ females (Table 1). All
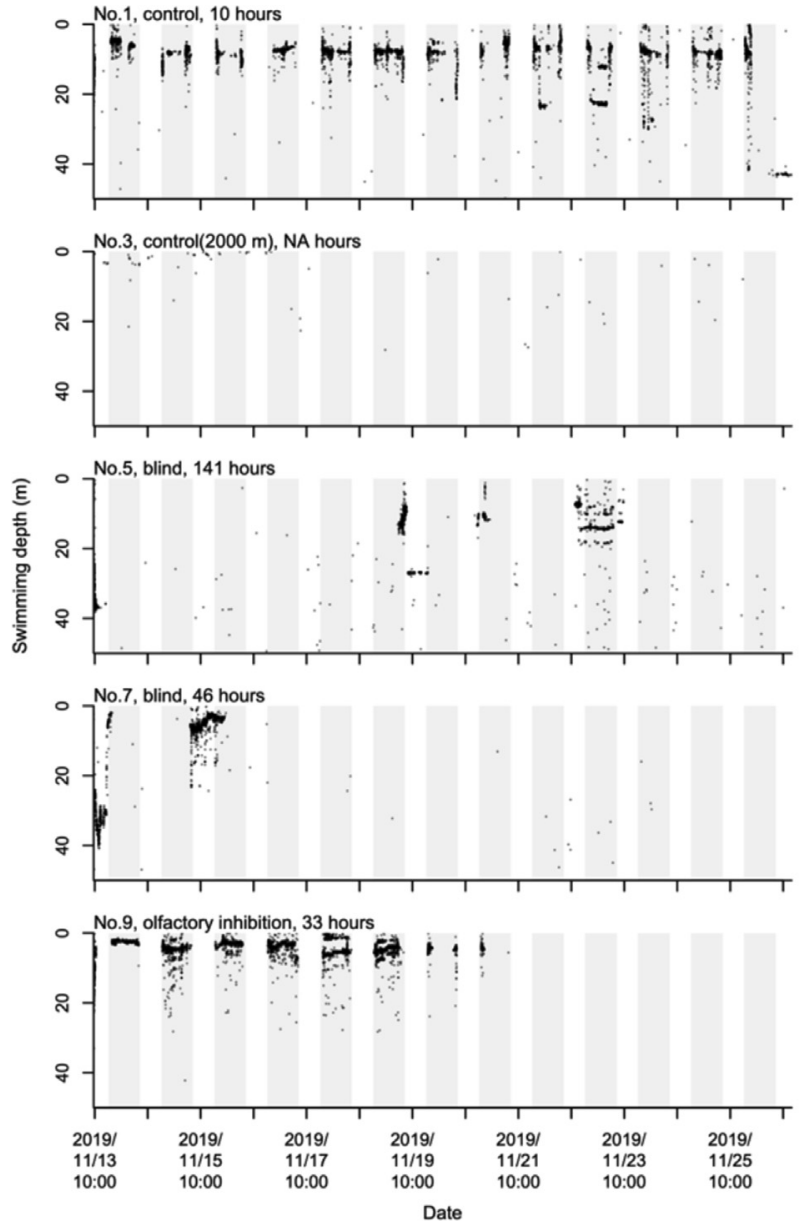

individuals were released in the same manner. We observed that the BLD individuals migrated offshore in the opposite direction to that of the CNT and OLF individuals. The data recovery rate for the number of releases is $100.0 \%$. The longest period of reception of the transmitter was 13 days, which was the duration until the receiver was retrieved.

Three transmitters were retrieved by fishing activity, and the recovery rate of devices for the number of releases was $33.3 \%$. The retrieval locations were concentrated around the fishing site, and the most distant point was $3.6 \mathrm{~km}$ away from the fishing site (\#9 of OLF). We were unable to obtain individual information for one of the recaptured individuals because it was re-released by the fisherman. The vinyl chloride sheet for BLD individuals had not been removed from the individuals 2 weeks after the tagging. In addition, the Vaseline injected into the nasal cavities of the OLF individuals had not fallen out 45 days after the tagging.
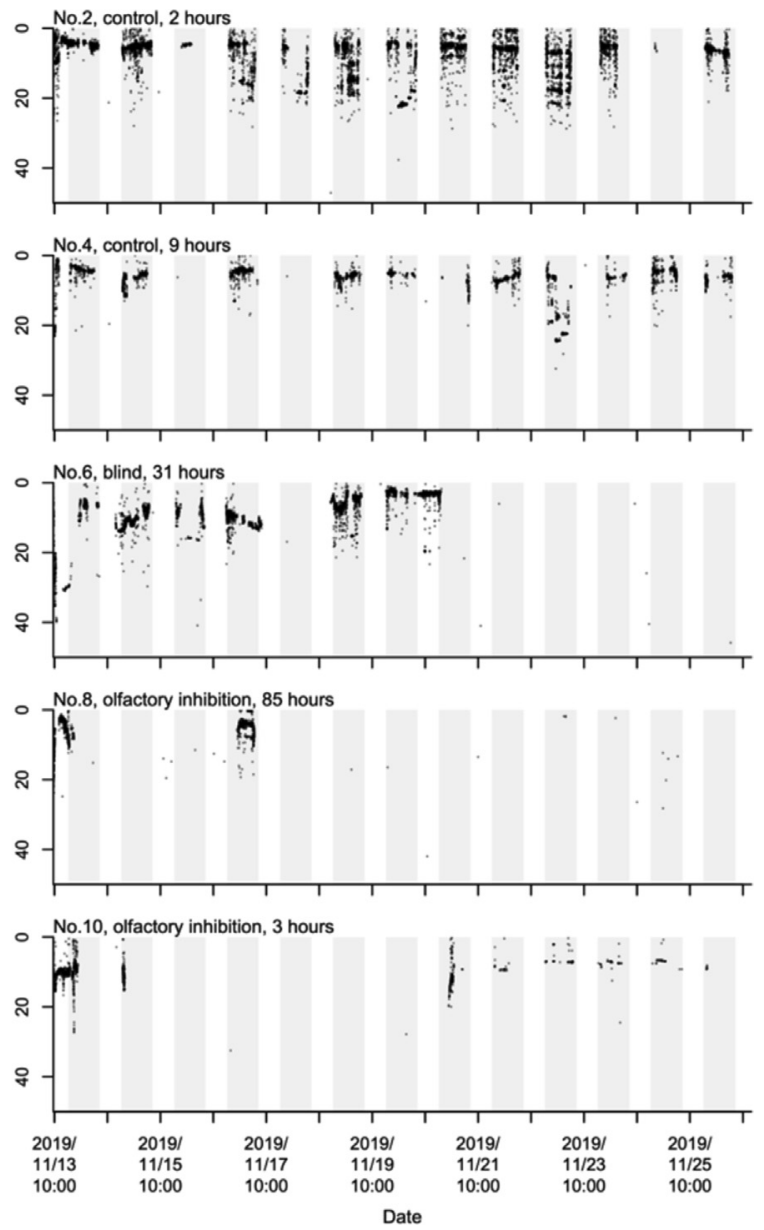

Fig. 3. Detected area and swimming depth on 10 tracked black rockfish from the release to the end of the survey. The detected area is color-coded for each receiver. Cyan is areal, orange is area2, and magenta is area3. The gray zone indicates the period from sunset to sunrise. The words above each graph indicate the ID, the type of condition and the return duration. No.1, 2 and 4 are signals from CNT individuals. No.3 was exceptionally released at $2000 \mathrm{~m}$ away from the fishing site. No.5-7 and No.8-10 each are signals from BLD and OLF individuals. 

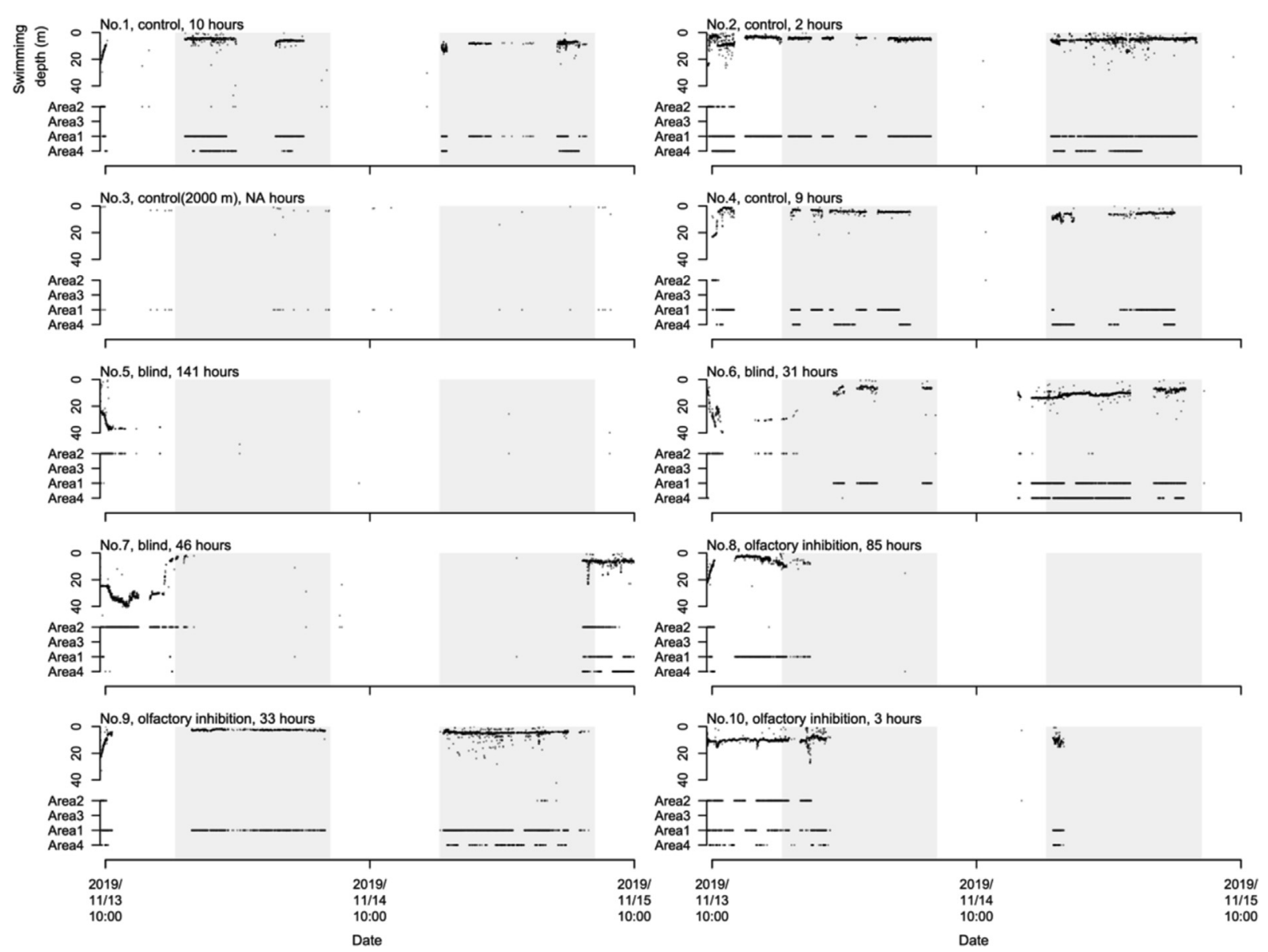

Fig. 4. Detected area and swimming depth on 10 tracked black rockfish during 24 h after release. The design of this figure is same as Fig. 3.

\subsection{Frequency and duration of reception in each area}

The total number of receptions for which IDs could be identified at each receiver was 57,537 , and there were receptions in Areas 1, 2, and 4 (Table 2). There were 33,937 receptions in Area 1, 11,330 receptions in Area 2, no reception in Area3, and 12,270 receptions in Area 4. The number of receptions between day and night differed greatly, with a total of 7744 receptions during the day and 49,793 receptions at night.

The individuals labeled \#1, \#2, and \#4 of CNT were detected until November 26, the end of the survey (Fig. 3). They tended to be detected more than the BLD and OLF individuals. All of the BLD individuals were detected in at least one area after release; however, none of the individuals were detected at the end of the survey. Individual \#10 of OLF had repeated short-term reception until the end of the survey, whereas \#08 and \#09 were only detected around the release with no reception at the end of the survey.
The CNT and OLF individuals mainly used the depth zone shallower than $10 \mathrm{~m}$ (CNT: $8.97 \pm 6.13 \mathrm{~m}$; mean \pm S.D.; OLF: $5.31 \pm 3.21 \mathrm{~m}$ ), whereas the BLD individuals tended to use a depth zone deeper than $10 \mathrm{~m}$, differing significantly from OLF individuals (BLD: $11.31 \pm 8.59 \mathrm{~m}$; CNT vs. OLF $(\mathrm{z}=-1.04$, $\mathrm{p}>0.05)$, CNT vs. $\operatorname{BLD}(\mathrm{z}=-1.34, \mathrm{p}>0.05)$, BLD vs. OLF $(\mathrm{z}=-2.38, \mathrm{p}<0.05))$.

\subsection{Characteristics of activity during return trip}

The individuals completing their return trips to the fishing site were three CNT, three BLD, and three OLF individuals (Table 2). Only an individual released from $2 \mathrm{~km}$ did not return. The time required to return was relatively short for $\mathrm{CNT}$ and OLF individuals (CNT: $6.67 \pm 4.93 \mathrm{~h}$; mean \pm S.D.; OLF: $16.33 \pm 18.58 \mathrm{~h}$ ). The return time of BLD individuals was significantly longer than that of the CNT individuals (BLD: $72.33 \pm 60.00 \mathrm{~h}$; CNT vs. OLF $(\mathrm{z}=1.20, \mathrm{p}>0.05), \mathrm{CNT}$ vs. $\mathrm{BLD}(\mathrm{z}=-3.18$, $\mathrm{p}<0.01)$, BLD vs. OLF $(\mathrm{z}=-1.99, \mathrm{p}>0.05))$. 
The process of the return trip was different for each individual condition (Fig. 4). The CNT individuals were detected at a depth of $10-20 \mathrm{~m}$ in Area 2 immediately after release. They then moved linearly to a shallower depth, and reception was scattered below $10 \mathrm{~m}$ in Areas 1, 2, and 4. After that, the reception in Area 2 decreased and only occurred in Areas 1 and 4 . In contrast, \#05, \#06, and \#07 of the BLD individuals were detected in areas $30 \mathrm{~m}$ or deeper in Area 2 following release and partly detected in Areas 1 and 4. Compared with other groups, daytime reception was frequently observed. OLF individuals were detected in Area 2 immediately after release and moved to the shallower waters, as did the CNT individuals. Next, OLF individuals were detected in Areas 1, 2, and 4. However, reception stopped after several hours. Individual \#8 from OLF was observed continuously in Area $184 \mathrm{~h}$ after stopping reception.

\section{Discussion}

\subsection{Ability to return and activity pattern of black rockfish}

Nine tagged black rockfish released $850 \mathrm{~m}$ from the fishing site completed the return, although the time required to return differed, and one control individual released $2 \mathrm{~km}$ from the fishing site did not return. It suggests that black rockfish around the Usujiri fishing port have the ability to return from distances less than $850 \mathrm{~m}$, and indicate an example of impossibility to return from more than $2 \mathrm{~km}$ away. In the genus Sebastes, return trips from $22.5 \mathrm{~km}$ away have been reported [4], so the returnable distance for black rockfish is likely relatively short.

The time required to complete the return for CNT individuals was $6.67 \pm 4.93 \mathrm{~h}$ [18] released Sebastes caurinus and Sebastes maliger $500 \mathrm{~m}$ away from their habitat and found that over 15 days was required for their return [19]. also released Sebastes inermis at $1.0-4.5 \mathrm{~km}$ from their habitat and found that some individuals returned within 4 days. Comparing these reports with our results, the time taken by tagged black rockfish to return was relatively short $[12,36]$. reported that tracked black rockfish did not leave the receiving range of one of the acoustic receivers (approximately $500 \mathrm{~m}$ ) for more than a week. Also, in this study, individuals were only detected around the fishing site for a maximum of 13 days after returning. Such a relatively narrow activity range, as well as the short returnable distance, may have contributed to the short time required to complete the return.
The signals of CNT individuals began being received from Areas 1 and 4 at around 5 p.m. in the evening and stopped being received at the same points at around $6 \mathrm{a} . \mathrm{m}$. in the morning. This indicates a large difference in the number of receptions during the day and at night. Previous studies have suggested that black rockfish are more active at night $[12,36]$ indicated that this species may prefer reefs and environments with many obstructions, suggesting that individual activity and use locations also differed during the day and night. In our study, the wave-dissipating blocks and structures around the fishing site at the Usujiri fishing port made it difficult to receive acoustic transmitters from the inside of the blocks, even though they were within the reception range. Divers in the vicinity have frequently observed black rockfish using the space of the blocks in the daytime. Thus, fewer receptions were likely detected for the tracked individuals in this study during the daytime because of their use of the space in the blocks.

\subsection{Sensory organs used for returning and site fidelity}

Differences were found for the characteristics of the return trip and swimming behavior between CNT and sensory-inhibited individuals. From the retrieved individuals, the vinyl chloride sheet used for visual inhibition and the Vaseline used for olfactory inhibition remained intact at the end of the study period suggesting that sensory inhibition was achieved in all individuals.

CNT individuals tended to be detected in Areas 1 and 4 near the fishing grounds after being in Areas 1, 2 and 4 for short periods around release. Yet there was no reception in Area 3. The characteristics of these return routes may have been influenced by the geographic environment and landmark obstacles at the study site [18]. showed that many $S$. caurinus and S. maliger individuals were found in or near reef areas during their return trips, suggesting that these species may have returned using rocky zones or landmark obstacles as visual cues. At our study site, there were no landmark obstructions besides the wave-dissipation blocks in Areas 3 and 4 , but kelp cultivation facilities anchored with foundations and ropes were established around Areas 1 and 2. It is possible that the presence of these landmarks influenced the observation that the CNT individuals' return routes were not through Area 3 or directly back to Area 4 and the fishing site.

The BLD individuals stayed for 5-6 h at a depth of about $40 \mathrm{~m}$ in Area 2 after continuous detection in Area 2 at release. The area with the $40 \mathrm{~m}$ depth is in 
the northeastern part of Area 2, and the result that BLD individuals used this area indicated that the BLD individuals had moved in a different direction, as observed during the release, from the CNT individuals. Subsequently, \#8 was observed in Area 1 after a period of no reception, so it was inferred that the individual had moved out of the reception range from the northeast part of Area 2 to Area 1. Ultimately, all three individuals returned to the vicinity of the fishing site but took over three times as long as the CNT individuals. These results suggest that visual cues were a major contributor to the route and duration of this species' return trip. These results also indicate that landmarks in the habitat are important [20]. reported that the return route became more linear and swimming speed increased from the vicinity of a characteristic obstacle that could be a landmark in the activity range of $S$. inermis. Therefore, the obstacles and reefs as landmarks may influence not only the determination of the return route, but also the swimming speed and characteristics of Sebastes species. In this study, the BLD individuals showed different activity patterns from the CNT individuals after completing their return, with frequent receptions during the day and no receptions at the end of survey. This suggests that the loss of this species' vision-i.e., its ability to sense landmarks in the surrounding environment-influenced its swimming speed and state, resulting in changes in the time required to return and diurnal activity patterns relevant to the site fidelity.

Still, the BLD individuals returned to the vicinity of the fishing site, although they took relatively longer to do so than the CNT individuals. This suggests that they had other sensory organs besides vision to detect direction and distance to the fishing site. Along with vision, olfaction is indicated as the primary sense used for return trip in other members of the genus Sebastes. The OLF individuals in this study took slightly longer to return than the CNT individuals. Although the effects of olfactory inhibition on the time and speed of the return trip may have been less than that of visual inhibition, the tagged individuals may have had difficulty receiving some of the information about the core area as a result of olfactory inhibition. The existence of two main types of olfactory cues associated with return trips and site fidelity can be hypothesized from previous studies $[8,21]$. One is habitat-specific olfactory cues. Many salmonids fishes partly use the olfactory cues of their native rivers to home and spawn at their birthplace $[9,6]$. The other possibility is olfactory cues derived from urine, feces, and body fluids emitted by conspecifics [27]. For example, Dascyllus aruanus preferred water from reefs in the habitat where it lived than that from reefs where the species did not live [33]. The fishing sites of the individuals in this study were covered with concrete wave-dissipating blocks, and a lot of seaweed had grown on them. These environments are similar to the areas favored by this species, and it was expected that many individuals of the same species could potentially inhabit the area around them. Therefore, olfactory cues from both the environment and conspecifics may have been present, and it is not possible to determine which was received during the return trip. Among the OLF individuals, $\# 8$ and \#9, which took a relatively long time to return, may have moved linearly from Area 2 to Area 1 after release, and then taken longer to reach the fishing site. The individuals had likely reached the vicinity of the fishing area using visual cues; however, olfactory inhibition probably prevented them from completing a quick return trip. Therefore, in black rockfish, the olfactory cues mentioned above might be more useful for discriminating the area closer to the core area than the visual cues.

Our research has focused on the effects of visual and olfactory sensations during homing behavior. Whereas, underwater noise can cause startle and alarm behavior of rockfish [26]. Therefore, it can be said that auditory sensation does affect the behavior of black rockfish, and differences in the sound environment of the study site should be considered in future studies.

Our results suggest that the return capability of the black rockfish is similar to that of other Sebastes species, with a relatively short returnable distance of less than $850 \mathrm{~m}$. Especially for animals with strong site fidelity, such as Sebastes, understanding the activity range and the typical returnable distances is important from the perspective of resource management. This knowledge can be used to establish a protection area for this species. This knowledge will also be critical for examining the effectiveness of the local catch-and-release measures for each fish size class of this species. Additionally, the detection of landmarks through vision and the recognition of core area environments and conspecifics individuals through olfaction may influence the route, speed, and duration of this species' return trip and site fidelity. For comprehensive management of this species, not only habitat but also the structures around the habitat, which can become landmarks, and the plants and animals from which olfactory cues is derived, should be considered. 


\section{Acknowledgments}

We profoundly thank Dr. H. Munehara, Y. Miyajima and S. Kaga who gave us the opportunity to conduct this study. We sincerely thank Drs. M. Nakaoka, Y. Mitani, J. Yamamoto, S. Katakura and $\mathrm{H}$. Mitamura for their valuable advices during the preparation of field survey and the submission this study as research paper. We would like to express our appreciation to S. Fukui, T. Kitagawa, D. Oshiyama, R. Ohtani, I. Tatsuoka, R. Soma, K. Mizutani, H. Hakoyama and Y. Nishimori who kindly helped the fieldwork. We thank Natalie Kim, PhD, from Edanz Group (https://en-authorservices.edanzgroup.com/) for editing a draft of this manuscript. Finally, we are grateful to anonymous reviewers for their helpful and critical comments on this manuscript. This work was supported by the Sasakawa Scientific Research Grant from The Japan Science Society, Grant number 2019-4097.

\section{References}

[1] Avens L, Lohman KJ. Use of multiple orientation cues by juvenile loggerhead sea turtles Caretta caretta. J Exp Biol 2003; 206:4317-25.

[2] Barsukov VV. A brief review of the system of the subfamily Sebastinae. J Ichthyol 1981;21:1-26.

[3] Bertz F, Hothorn T, Westfall P. Multiple comparisons using R. Boca Raton, FL: Champman \&Hall/CRC; 2010.

[4] Carlson HR, Haight RE. Evidence for a home site and homing of adult yellowtail rockfish, Sebastes flavidus. J Fish Res Board Can 1972;2299:1011-4.

[5] Dodson JJ. The nature and role of learning in the orientation and migratory behavior of fishes. Environ Biol Fish 1988; 23(3):161-82.

[6] Døving KB, Westerberg H, Johnsen PB. Role of olfaction in the behavioral and neuronal responses of Atlantic salmon, Salmo salar, to hydrographic stratification. Can J Fish Aquat Sci 1985;42(10):1658-67.

[7] Gerking SD. The restricted movement of fish populations. Biol Rev 1959;34:221-42.

[8] Harada E. A contribution to the biology of the black rockfish. In: Sebastes inermis Cuvier et Valenciennes, vol. 10. Publication of the Seto Marine Biological Laboratory; 1962. p. $163-217.2$.

[9] Hara TJ. An electrophysiological basis for olfactory discrimination in homing salmon: a review. J Fish Res 1970; 27:565-86. Board of Canada.

[10] Heilprin DJ. The role of olfaction in the homing ability of the blue rockfish Sebastes mystinus in Carmel Bay, California. MS thesis. USA: Moss Landing Marine Labs and San Jose State University; 1992 [published].

[11] Hokkaido Prefecture. Hokkaido fisheries today. Hokkaido, Japan: Hokkaiod Suisan Hakusho; 2015 [in Japanese].

[12] Kang KM, Shin HO. Movement ranges and routes of black rockfish Sebastes schlegeli in summer and autumn from acoustic telemetry. Fish Aquat Sci 2006;9(2):91-6.

[13] Larson RJ. Territorial behavior of the black and Yellow rockfish and Gopher rockfish (Scorpaenidae, Sebastes). J Marine Biol 1980;58(2):111-22.

[14] Letty J, Aubineau J, Marchandeau S, Clobert J. Effect of translocation on survival in wild rabbit (Oryctolagus cuniculus). Mamm Biol 2003;68:250-5.
[15] Lohmann KJ, Pentcheff ND, Nevitt GA, Stetten GD, ZimmerFaust RK, Jarrard HE, et al. Magnetic orientation of spiny lobsters in the ocean: experiments with undersea coil systems. J Exp Biol 1997;198:2041-8.

[16] Love MS, Yoklavich M, Thorsteinson LK. The rockfishes of the Northeast Pacific. Berkeley, CA: University of California Press; 2002.

[17] Matthews KR. An experimental study of the habitat preferences and movement patterns of copper, quillback, and brown rockfishes (Sebastes spp.). Environ Biol Fish 1990a;29: 161-78.

[18] Matthews KR. A telemetric study of the home ranges and homing routes of copper and quillback rockfishes on shallow rocky reefs. Can J Zool 1990b;68(11):2243-50.

[19] Mitamura H, Arai N, Sakamoto W, Mitsunaga Y, Maruo T, Mukai Y, et al. Evidence of homing of black rockfish Sebastes inermis using biotelemetry. Fish Sci 2002;68:1189-96.

[20] Mitamura H. Studies on homing behaviour and site fidelity in aquatic animals using biotelemetry. Nippon Suisan Gakkaishi 2015;81(4):651-4 [in Japanese].

[21] Mitamura H, Arai N, Sakamoto W, Mitsunaga $Y$, Tanaka H, Mukai $Y$, et al. Role of olfaction and vision in homing behavior of black rockfish Sebastes inermis. J Exp Mar Biol Ecol 2005;322:123-34.

[22] Nakagawa M. Studies on the stock enhancement technology of the black rockfish Sebastes schlegeli. Bull Fish Res Agency 2008;25:223-87 [in English, with English Abstract].

[23] Nishi T, Kawamura G. Magnetosensitivity in the darkbanded rockfish Sebastes inermis. Nippon Suisan Gakkaishi 2006; 72(1):27-33 [in Japanese, with English Abstract].

[24] Nemoto Y, Ishida T. Ecology and stock status of black rockfish, Sebastes inermis, along the coast of Fukushima. Bull Fukushima Prefecture Fish Exp Stn 2006;13:63-76 [in Japanese].

[25] Pearcy WG. Movements of acoustically-tagged yellowtail rockfish Sebastes flavidus on Heceta Bank, Oregon. Fish Bull 1992;90(4):726-35.

[26] Pearson WH, Skalski JR, Malme CI. Effects of sounds frim geophysical survey device on behavior of captive rockfish (Sebastes spp.). Can J Fish Aquat Sci 1992;49:1343-56.

[27] Polkinghorne CN, Olson JM, Gallaher DG, Sorensen PW. Larval sea lamprey release two unique bile acids to the water at a rate sufficient to produce detectable riverine pheromone plumes. Fish Physiol Biochem 2001;24:15-30.

[28] R Core Team. R: a language and environment for statistical computing. Vienna, Austria: R Foundation for Statistical Computing; 2020. https://www.R-project.org/.

[29] Reese ES. Orientation behavior of butterflyfishes (family Chaetodontidae) on coral reefs spatial learning of rout specific landmarks and cognitive maps. Environ Biol Fish 1989; 250:79-86.

[30] Sasaki M, Mitsutani N, Nishiuchi S, Shiokawa F, Takahashi T. Age and growth of Sebastes schlegeli in the coastal waters of Shiribeshi Subprefecture, Hokkaido, Japan. Bull Jpn Soc Fish Oceanogr 2004;68:232-8 [in Japanese, with English Abstract].

[31] Sasakura T. Underwater biotelemetry. J Acoust Soc Jpn 2016; 72(4):207-12 [in Japanese].

[32] Shin HO, Tae JW, Kang KM. Acoustic telemetrical measurement of the movement range and diurnal behavior of rockfish (Sebastes schlegeli) at the artificial reef. J Kor Fish Soc 2005;38(2):129-36.

[33] Sweatman H. Field evidence that settling coral reef fish larvae detect resident fishes using dissolved chemical cues. J Exp Mar Biol Ecol 1988;124:163-74.

[34] Tomiyasu M, Shirakwa H, Iino Y, Miyashita K. Tracking migration of pacific herring Clupea pallasii in a coastal spawning ground using acoustic telemetry. Fish Sci 2018; 84(1):79-89.

[35] Willis TJ, Millar RB, Babcock RC. Detection of spatial variability in relative density of fishes: comparison of visual census, angling, and baited underwater video. Marine Ecol Prog Serie 2000;198:249-60. 
[36] Zhang Y, Xu Q, Alós J, Liu H, Xu Q, Yang H. Short-term fidelity, habitat use and vertical movement behavior of the black rockfish Sebastes schlegelii as determined by acoustic telemetry. PloS One 2015;10(8):e0134381.
[37] Zeller DC. Home range and activity patterns of the coral trout Plectropomus leopardus (Serranidae). Mar Ecol Prog Ser 1997;154:65-77. 